\title{
Gruppo Prometeo's volunteering experience during the COVID-19 pandemic: an example of self-organization and heutagogy
}

\author{
Sara Bighini
}

Gruppo Prometeo (Student Association of the Alma Mater Studiorum - University of Bologna), Bologna, Italy

This commentary is inspired to a presentation given at the 37th Medical Education Conference organized by the Korean Society of Medical Education and the Korea Association of Medical Colleges (June 3-4, 2021) under the theme of "Medical education in the era of pandemic" and reports the recent experience of "Gruppo Prometeo," an independent, anti-fascist, anti-racist, gender friendly, and anti-stigma association of medical students, founded in 1992 at the School of Medicine of the Alma Mater Studiorum-University of Bologna. This student association has always tried to go beyond the biomedical model [1], also as regards medical students' role.

The coronavirus disease 2019 (COVID-19) pandemic worked as a magnifying glass for many socio-political problems, which already existed before, and the same is true in medical education. Together with the need for a broader scientific model, beyond the biomedical one, in order to understand health and illness in an individual, it is necessary to resort to more inclusive approaches to medical practice, which must include attention to non-biomedical factors and variables [2].
Gruppo Prometeo's answer during the first and second wave of the COVID-19 pandemic consisted in a series of different initiatives. The first was "A un metro da te (Just one meter from you)," a self-organized voluntary project, which involved almost 300 medical students in low-skilled medical and/or bureaucratic tasks in order to provide relief to all the professional workers in the local hospitals, which were extremely under pressure at that time. Then, in March 2021, there was the contact tracing experience managed in collaboration with the Bologna Public Health Department. In addition, during those months, we organized a cycle of conferences and some seminars, focusing, on one hand, on burnout among medical students, coping mechanisms and COVID-19 fatigue and, on the other hand, on the vaccination campaign, the Cuban vaccine and the different health policies to face the pandemic crisis. All these initiatives have something in common: the promotion of a proactive role of the medical student in the healthcare system, which changes from being just a passive learner to becoming an active part of the system.
Received: October 26, 2021 • Revised: November 10, 2021 - Accepted: November 10, 2021 Corresponding Author: Sara Bighini (https://orcid.org/0000-0002-1800-8380)

Gruppo Prometeo (Student Association of the Alma Mater Studiorum - University of Bologna), Via Rino Pancaldi, 6, I-40138 Bologna BO, Italy

Tel: +39.3347321910 Fax: +39-3347321910 email: sara.bighini@studio.unibo.it
Korean J Med Educ 2021 Dec; 33(4): 445-447 https://doi.org/10.3946/kjme.2021.213

eISSN: 2005-7288

(C) The Korean Society of Medical Education. All rights reserved. This is an open-access article distributed under the terms of the Creative Commons Attribution Non-Commercial License (http:// creativecommons.org/licenses/by-nc/3.0/), which permits unrestricted non-commercial use, distribution, and reproduction in any medium, provided the original work is properly cited. 
Our experience in Bologna, which was completely self-organized by medical students, is a clear example of "the importance of learning by participation, where the mode of learning is authentic work" [3] and goes beyond the traditional model of learning by acquisition. This approach shows some of the advantages connected with heutagogy (as compared to pedagogy) [4] in medical education and traineeship, since students start to be considered as actors in building their own undergraduate education [5].

In addition, our student community also made some collective reflections on the organization of clinical clerkships in Italy, as a fundamental aspect of medical education. In fact, with the widespread outbreak of COVID-19, our university decided to stop all medical traineeships. At first glance, this decision could seem counterintuitive since hospitals needed more and more people working to deal with the emergency. The explanation is that our mainly observational traineeships did not provide the clinical skills required to help in everyday clinical work and that is also the reason why all the self-organized initiatives consisted mainly in bureaucratic tasks. Starting from this awareness, we created an assembly process with our university mates on the lack of practical experience in our education. Assuming that medical education and medical practice are two sides of the same coin, we wrote what we called a "Clerkship treaty," which denounces the frustration connected with a mainly theoretical approach and offers possible improvements of our university system.

This treaty, which we are now presenting both to the general director of our university hospital and to the dean of our school of medicine, contains some proposals to deeply reform the clerkship system by (1) enhancing and institutionally acknowledging the role of the medical tutor, (2) promoting peer-to-peer teaching and interprofessional clerkships, and (3) acknowledging the value of trainees as resources for the healthcare system and enlarging the medical training network also involving community health structures [6].

We are aware that our experience has some "sitespecific" aspects, which reflect the Italian medical education model and its pros and cons, but we also believe that the will of organizing ourselves and building an institutional dialogue among all the actors of the healthcare system could genuinely start an alliance towards continuous improvement and give a cue also to other medical students in the world who will decline this inspiration to make it fit for their own healthcare and university system.

In conclusion, as medical students, we chose not to be neutral and it turned out to be a good choice.

\section{ORCID:}

Sara Bighini: https://orcid.org/0000-0002-1800-8380

Acknowledgements: None.

Funding: No financial support was received for this study.

Conflicts of interest: No potential conflict of interest relevant to this article was reported.

Author contributions: All work was done by Sara Bighini.

\section{References}

1. Farre A, Rapley T. The new old (and old new) medical model: four decades navigating the biomedical and psychosocial understandings of health and illness. Healthcare (Basel). 2017;5(4):88.

2. Tresolini CP, Shugars DA. An integrated health care model in medical education: interviews with faculty and administrators. Acad Med. 1994;69(3):231-236.

3. Gonzalo JD, Dekhtyar M, Hawkins RE, Wolpaw DR. 
How can medical students add value?: identifying roles, barriers, and strategies to advance the value of undergraduate medical education to patient care and the health system. Acad Med. 2017;92(9):1294-1301.

4. Parslow GR. Commentary: Heutagogy, the practice of self-learning. Biochem Mol Biol Educ. 2010;38(2):121.

5. Bansal A, Jain S, Sharma L, Sharma N, Jain C, Madaan M. Students' perception regarding pedagogy, andragogy, and heutagogy as teaching-learning methods in undergraduate medical education. J Educ Health Promot. 2020;9:301.

6. Khabaz Mafinejad M, Ahmady S, Soltani Arabshahi SK, Bigdeli S. Interprofessional education in the integrated medical education and health care system: a content analysis. J Adv Med Educ Prof. 2016;4(3):103-110. 